\title{
The Future of Biodegradable Plastics from an Environmental and Business Perspective
}

\author{
Hani Chbib ${ }^{1}$, Marwa Faisal' ${ }^{2}$, Amal El Husseiny², Irene S Fahim ${ }^{3 *}$ and Nicola M Everitt ${ }^{4}$ \\ ${ }^{1}$ School of Business Administration, Nile University, Egypt \\ ${ }^{2}$ Center of Nanotechnology, Nile University, Egypt \\ ${ }^{3}$ Department of Industrial Engineering and Service Management, Nile University, Egypt \\ ${ }^{4}$ Department of Mechanical, The University of Nottingham, England \\ *Corresponding author: Irene S Fahim, Department of Industrial Engineering and Service Management, Nile University, Juhayna \\ Square, Sheikh Zayed City, Giza, Egypt
}

\begin{abstract}
Synthetic plastic waste is a major environmental issue around the world. There are several policies adopted in many regions to save the environment. Moreover, Governments and businesses are restraining synthetic plastics either by searching for a better alternative, or by reducing the public and industrial consumption of synthetic waste. However, the problem is finding a biodegradable and a price-competitive alternative for synthetic waste. This review paper studies markets for biodegradable and synthetic plastics and also the governmental policies being adapted around the world to combat synthetic plastics were analyzed. Additionally, the main issues that face developing countries before adapting environment-friendly policies were taken into consideration in this review paper. The authors aim at finding a solution for the price issue in a developing country like Egypt, as its results may as well reflect on several developing countries around the world. The market analysis indicates a very promising future for biodegradable plastics in developed countries, with CAGR levels reaching 20\% in some industries. Meanwhile, from an environmental perspective, strict policies all around the world are needed to battle synthetic plastics. This need is recognized in developed countries; however, in developing countries, the price is still the issue. Nonetheless, the authors have been capable of conducting a method to produce plastic bags from chitosan pellets that would cut the costs to 2,000 USD/Ton. A price as such would make biodegradable plastics almost as competitive as synthetic plastics, even in developing countries.
\end{abstract}

\section{Highlights}

a) The only factor preventing Egypt from being environment friendly is money.

b) Governments' strict policies are essential in making an environment change effective.

c) Plastic waste falling in our oceans is expected to reach 160 million tons in 2025.

d) Biodegradable plastic bags can soon be as competitive as synthetic bags.

Keywords: Plastics; Biodegradable plastics; Shrimp shell waste; Waste; Feasibility

\section{Introduction}

Over the last two hundred years, the world has become dependent on synthetic plastics, from industrial applications to consumer use [1] plastics are among the prime products in many different applications, where huge masses are used. The most important feature of plastics can be the flexibility, abundance and durability of the raw materials; however, this feature comes with a side effect. Scientists claim that every piece of synthetic plastics that has ever been made is still floating somewhere in the oceans or lying down in some open areas around the world [2]. Researchers have been looking for some more environment friendly features to battle our dependence on plastics. However, most of these alternatives are still not that competitive with synthetic plastics, which is why 
they are trying to limit the use of plastics instead. Actions that the European Union has taken to reduce the dependence on plastic bags, for instance, has been relatively successful, as while the global average consumption of plastic bags is 513 bags per person per year, the average in the European Union is now 80, going down to around 20 in some specific countries [3]. In short, there are two ways to fight this environmental problem, either by banning or controlling the use of plastics, or by finding an alternative. The problem with the first alternative is that it would take a long time with full state-level commitment to change the culture towards plastics. Meanwhile, the problem with the second alternative is reaching the competitive price compared to plastics. However, researchers around the world expect to find an alternative soon that is more price competitive than oil-based plastics [4]. By dividing the world into developed and developing countries, we find that state-level policies to combat plastics are more successful in developed countries, in addition to the fact that biodegradable plastics, which (may not be that competitive with synthetic plastics) have a rapidly growing market in these countries. Meanwhile, in a developing country like Egypt, it is difficult and expensive to implement such a policy, due to the high cost of implementing such a policy and moving to an environment-friendly alternative [5]. On the other hand, the markets for biodegradable plastics are rapidly growing, one possible alternative is to produce biodegradable plastics from Chitosan, that is taken from shrimp shell waste in Egypt. Globally, the price for chitosan is not competitive, given that 1 ton of plastics costs around 1500USD [6] while 1 Ton of chitosan for industrial use is priced at 10,000USD [7]. However, researchers at Nile University, in cooperation with Nottingham University have found a new method to produce chitosan that may reduce the final cost to around 2,000USD, which would make it after comparing the expected density of chitosan with the density of LDPE, more competitive to use chitosan to produce plastic bags. Chitosan is the plastic alternative investigated; however, in order to make chitosan a proper alternative for plastics, some other natural additives should be added. The additives will enhance the physical and mechanical properties of chitosan.

\section{Hypothesis}

The proposed hypothesis is that biodegradable plastics can actually compete in the near future with polymer-based plastics. Despite the fact that polymer based plastics have social costs on both the society and environment, the competition we are addressing is mainly on the economic cost resulting in the price of these products, as social costs are not taken into account especially in poorer economics like the Egyptian. Therefore, if we succeed in making biodegradable plastics economically competitive, it can be the norm not to harm the environment anymore with polymer-based plastics. The question that persists though is, how competitive can biodegradable plastics be in the near future?

\section{Biodegradable Plastics \\ Biodegradable Plastics Worldwide}

The market in North America, Europe and Asia has grown around 15\% CAGR from 2012 to 2017. Therefore, global demand is expected to hit 525000 tons in 2017 [8]. The biodegradable Plastics market is a growing market globally. In North America particularly, biodegradable plastics market has grown significantly due to the fact that biodegradable plastics have become more cost competitive with petroleum-based plastics [7]. The market in the United States of America alone is expected to be worth of 3.4 Billion USD in 2020 , with an annual CAGR of $10.8 \%$ by a five-year period ending 2020 [9]. In 2012, Europe was the dominant market for biodegradable plastic products with $55 \%$ of global consumption; North America was second with 29\%, followed by Asia with $16 \%$ [8]. The biodegradable plastics market in Europe is expected to further grow with a $20 \%$ CAGR year [10]. In fact, reports expect the market of biodegradable plastic products in the EU to grow over 300,000 Tons in 2020 [11]. The United Kingdom currently imports 3000 Tons of biodegradable plastic bags and domestically produces 1000 Tons [12].

\section{Biodegradable Plastics in Egypt}

The market for biodegradable plastics is not well established in Egypt. The Egyptian consumer mindset still is not aware enough of the real impact that an individual consumer can have on the environment by choosing to shift into more environment friendly products, like biodegradable plastics. The Egyptian market is a poor market in terms of financial numbers and thus the Egyptian manufacturer always has a preference for the cheapest alternative no matter how damaging this alternative can be on the environment [5]. In addition, the ministry of environment, according to [5] is not taking enough procedures to tackle the environmental issues in Egypt in general.

\section{Biodegradable Plastics Applications Biodegradable Plastics Applications Worldwide}

Biodegradable Plastics are used in many applications worldwide. Applications very from bio-waste bags and shopping bags into relatively more complicated technical equipment products [11]. Precisely, according to this study, about $68 \%$ of 100000 tons of biodegradable plastics produced in 2015 in the European Union are used as biodegradable plastic bags, $21 \%$ in plastic packaging, $7 \%$ in consumer goods and the rest $4 \%$ in several other uses. These numbers are expected to grow to 320000 tons in 2020, with only $\% 57$ for biodegradable plastic bags, $\% 31$ for plastic packaging, $\% 7$ for consumer goods, and $\% 5$ for other uses [11].

\section{Biodegradable Plastic Applications in Egypt}

Except for the fact that some supermarkets are using compostable plastic bags, there is no relevant information upon 
which we can define the size or even the existence of a market for biodegradable plastics in general. Biodegradable plastics are, thus, a new concept to the Egyptian market.

\section{Biodegradable Plastic Bags \\ Biodegradable Plastic Bags Globally}

The European Union has an environmental strategy to reduce the usage of synthetic bags which also paves the way for biodegradable plastic bags as the best alternative in the European market [3] Italy, and lately France banned entirely the use of plastic bags [3]. In comparison, in the United States of America, the consumption of biodegradable plastic bags was reported to be about 95 billion biodegradable plastic bags yearly (conservingnow.com, 2016). Upon the authors assumption, the average weight of 1 plastic bag is about $12 \mathrm{~g}$. The overall American consumption of biodegradable plastic bags is about twice that of the United Kingdom.

\section{Biodegradable Plastic Bags in Egypt}

The situation for biodegradable plastics is not that different when it comes to biodegradable plastic bags [12] The market for biodegradable plastic bags in Egypt is dominated by petroleumbased plastics. There are no reports that prove that biodegradable plastic bags as an industry even exist in Egypt; however, some reports suggest that a big supermarket chain, KheirZaman which is a well-known hyper market in Egypt is importing biodegradable bags to promote their cause of a better environment in Egypt. The authors think, this as a sign that the market for biodegradable plastic bags might be well established in the middle-far future with the increased awareness of the younger generations, but not the near future. D2W, the technology through which these bags were made, is a new technology that makes convenient plastics biodegradable by adding some oxidants at the manufacturing level. "It is the only oxo-biodegradable (controlled-life) plastic additive to be awarded an internationally recognized eco-Label [13]. The additive is used in the manufacturing of plastic bags and plastic packaging. Also, only about $1 \%$ inclusion rate is needed to control the life of the plastic material [13]. This additive material is provided solely from a UK based manufacturer, which means that in the case of KheirZaman, this material is imported.

\section{Compostable Bags and Their Material Compostable Bags and Their Material Worldwide}

Reports suggest that in 2015, 50\% of polymers used in compostable and biodegradable products were stretch-copolyester compounds, $20 \%$ PLA, $15 \%$ co-polyester, $13 \%$ PLA copolyester compounds and $\% 2$ of other compounds [11].

\section{Compostable Bags and their Material in Egypt}

According to [5] companies that try to go environmentally clean by using materials that are environmentally friendly get out of the market for the simple fact that the Egyptian plastic market is extremely competitive [5].

\section{Synthetic Plastic Bags}

The materials used in manufacturing synthetic plastic bags globally are either polypropylene or polyethylene, high or low density of each. Both these materials are petrochemical compounds [5].

\section{Synthetic Plastic Bags Worldwide}

When it comes to the usage of traditional synthetic bags worldwide, it is quite noticeable that synthetic plastic bags are much less used in more developed countries. Countries with more individual awareness regarding global environment issues record fewer numbers of plastic bags used per individual. In the European Union alone, the average is about 200 plastic bags per individual [3]. However, the averages differ between different countries that in countries like Greece, Poland, Portugal, and Latvia the average is 514 bags per person, 468 of which are single-time use bags [3]. The average gets as low as about 80 bags per individual in countries like the UK and Germany, and even as low as 20 bags in Ireland [3]. A huge portion of these plastic bags are imported from east Asian countries for relatively low prices, which is why they still have a relatively big share of the European market. However, a country like Italy has quite a history with banning plastic bags, while France started to ban plastic bags recently in June 2016. Finally, huge taxes are being added to plastic bags to push European manufacturers to choose biodegradable plastic bags instead of the traditional, environment endangering synthetic plastic bags [3].

\section{Synthetic Plastic Bags in Egypt}

Given the developing characteristics of the Egyptian market, synthetic plastic bags have quite an advantage due to the fact that it is much cheaper to produce a plastic bag from petrochemical materials in comparison to biodegradable plastic bags [5]. The Egyptian market for plastic bags uses a total of 1 million tons of polyethylene; 600,000 tons are produced from the Egyptian gas field, that is high-density polyethylene; and 400,000 tons are imported from abroad as low-density polyethylene [5]. The plastic bags industry in Egypt makes up about $20 \%$ of the plastic industry in Egypt. Out of 1276 factories making up the Egyptian market in 2012, 265 factories worked on the plastic bags and plastic packaging sectors [14]. These factories produced a total of $1,000,000$ tons of plastic bags and packaging per year [5].

\section{Global Exporters and Importers of Plastic Worldwide}

Reports show the United States are on top of the list of plastic bags importers with 2.7 billion USD worth of imports in 2016. This accounts to about $18 \%$ of plastic bags import worth on global bases [15] Second on the list is Japan with about 1.5 billion USD worth of plastic bags imported, $10 \%$ of the plastic bags imports worth on global bases. Third on the list are both Germany and the UK, with about 1.05 billion USD worth of plastic bags imported, about 7\% each of the worth of plastic bags imported on global bases [15]. 


\section{Exporting Market for Egyptian Plastic Manufacturers}

Most of the plastic produced in Egypt is produced as a supplementary product for local industries, unlike East Asian countries, Egypt does not rely on exporting plastic products as a part of its economic system.

\section{Plastic Bags Physical Properties}

The density of a synthetic plastic bag slightly differs according to the type of raw material used. However, it is still between 0.9 and $0.965 \mathrm{~g}$ per $\mathrm{cm} 3$ [16]. For instance, low density polyethylene (LDPE) density ranges between 0.916 and $0.925 \mathrm{~g}$. while high density polyethylene (HDPE) density ranges between 0.941 and $0.965 \mathrm{~g}$ [16]. The approximated dimensions of a flat plastic bag before production is $65 \times 25 \mathrm{~cm}$. However, the most important and critical part of a plastic bag is the required thickness of a plastic bag. The UK standard for a plastic bag is 40 microns, while sizes between 35 and 50 are also acceptable. Also, in the USA the standard is 50 microns. Therefore, the thickness of a plastic bag lies between 35 for thin plastic bags and 50 for thick bags [17] Therefore, approximately the volume of plastic in a thin plastic bag will be $0.0035 \times 60 \times 25=5.25 \mathrm{~cm}^{3}$; and the volume of a thick bag will be $0.005 \times 60 \times 25=7.5 \mathrm{~cm}^{3}$. The corresponding g needed for each of the received values are $5.25 \times 0.925=4.86 \mathrm{~g}$, and $7.5 \times 0.925$ $=6.94 \mathrm{~g}$. The conclusion specifies that the weight of an average supermarket bag can take between 4.86 and $6.94 \mathrm{~g}$. Given the fact that 1 ton of Polyethylene costs between 1200 and 1500 USD, which accounts to between 21,000 and 27,000 EGP [13] one plastic bag can cost between 0.12 and 0.19 EGP, the price differs according to type of plastic and market fluctuations. That is only taking into account the direct material costs included in producing the plastic bags, without any direct labor, and indirect costs that might be incurred and taxes. Comparatively, while the market price for 1 ton of Polyethylene is about 25000 EGP, the market price for 1 ton of chitosan is USD10,000 [17] which equals about 175,000 EGP, that is 7 times that of polyethylene.

\section{Cost of Chitosan}

\section{Cost of Chitosan Worldwide}

Studies show that the market and applications for chitosan are growing rapidly on global bases. The industry size for chitosan in the United States of America alone is about 1.52 billion USD [18]. Its application includes water treatment, industrial applications, cosmetics, biomedicine and pharmaceuticals, food and beverages, and agrochemical products and other applications. The CAGR growth is expected to be about $16 \%$ annually, with most of the growth expected in biomedicine and pharmaceuticals in the near future [18]. The high CAGR level also suggests that the market in the United States of America alone in 2024 alone is going to reach 5 billion USD. The dollar price for 1 ton of chitosan differs depending on the quality provided and application needed; the price ranges between 10,000 USD and 1 million USD, with the average industrial price at 10,000 USD per 1 Ton [17]. The quality and application of
Chitosan differs heavily driving the huge difference in the price of chitosan.

\section{Cost of Chitosan in Egypt}

The expected cost of producing chitosan in Egypt is expected to lie between 50 and 500 USD per $1 \mathrm{Kg}$, given that it is not commonly used for industrial purposes but for pharmaceutical uses, which are relatively costly and limited. As well, given that Egypt is just a part of the world and there hasn't been an information of another method for producing relatively cheap chitosan from Shrimp shells. By applying the three steps method that [19] have applied, it would cost around 7,000USD (around 126,000 EGP) to produce 1 ton of chitosan, which is $30 \%$ cheaper than the international standard of 10,000USD. However, reducing the costs with $30 \%$ would not be enough to make chitosan competitive with synthetic plastics which are priced around 1,500USD. A further step would actually be required, that is recycling the waste generated from the process. We can save up to 5000 USD of raw materials per ton treated by recycling the expensive chemicals alone. And as a result, the costs would be reduced to 2000USD instead of 7000, which can be much more competitive with Synthetic Plastics if applied.

\section{Amount of Plastic Waste}

\section{Amount of Plastic Waste Worldwide}

Plastic waste is a special sort of waste given the fact that it does not degrade naturally and thus every plastic peace ever produced on this earth is still somewhere on this earth. every year, more than 8 million tons of plastic waste end up in our oceans [18] that is expected to build on and reach a total of 160 million tons in 2025. Global consumption of Plastic is estimated to be about 300 million tons in 2015. Between $22 \%$ and $43 \%$ Only of the plastic used worldwide is disposed of in landfills, which takes up valuable spaces and wastes the plastic resources [20]. Meanwhile, "recycling or burning plastics for energy has the potential to minimize these problems. However, burning plastic for energy requires air emissions control and produces hazardous ash, all while being relatively inefficient" [21]

\section{Amount of Plastic Waste in Egypt}

Out of the 1 million tons of plastic bags and packaging that goes into production, about $15 \%$ goes as industrial waste while the rest ends up with time as household waste, by the time its utility is ended [5]. Between 0 and $25 \%$ of rural areas' waste is being collected, while in some urban areas this percentage increases to about $95 \%$ [22]. $12 \%$ of the municipal solid waste collected is actually plastic, whilst $60 \%$ is organic waste. Also, $68 \%$ of this waste is collected from households while $5 \%$ is collected from the several industries in Egypt [22]. Sadly, 88\% of the Municipal Solid Waste ends up dumped in open areas, $8 \%$ is composted,2\% is recycled and $2 \%$ is landfilled. The waste problem in Egypt is a major problem, and most importantly when it comes to plastic it is a very serious problem given plastic is not naturally biodegradable [5]. The experimental 
start of the buying of trash from the citizens in Cairo. Tackling the waste problem in Cairo, the Egyptian government in March 2017 started purchasing municipal solid waste from the citizens through two small shops in Heliopolis in Cairo. The plan is to promote a waste separation from the source strategy to be implemented in each and every household in Cairo in the future. This might help in solving the waste problem in Egypt in the coming years [23].

\section{Shrimp Shell Waste}

Seafood waste is the main resource of chitosan. This includes, any crustaceans such as shrimps, crab, lobster and fish, as well as many other creatures commonly found in the sea [24]. Our focus in this paper will emphasize waste from shrimp as a starting point. Furthermore, these creatures contain in their waste proteins, and calcium carbonates, items that have several and some critical industrial applications. However, which are yet not that well utilized on a global level. For instance, aside from chitosan, calcium carbonates can be used in many pharmaceutical, agricultural, construction, and paper applications. Meanwhile, Proteins can be used as fertilizers and animal feeds [24]. To make the issue clearer, in the US alone, half of their seafood consumption was thrown away and discarded as waste between 2009 and 2013 [25]. with all its value adding components.

\section{Shrimp Shell Waste Worldwide}

About 6 to 8 Million Tons of seafood Waste are produced yearly globally, 1.5 million tons in South East Asia alone. 1 ton of shrimp shell waste is worth about 100USD to 120USD globally [24]. Seafood shells are known to contain calcium carbonate, chitin, and protein [24].

\section{Shrimp Shell Waste in Egypt}

Egyptian fisheries produce annually between 5,500 tons and 10,000 tons of shrimps; however, the numbers differ yearly [26]. Numbers are expected to be closer to the highest records, the most logical assessment is about 9000 tons, out of which 7500 Tons are expected to be derived from Izbet El-Borg near Demiatta alone [26]. Shrimp shells account to about 2,500 tons in Izbet El Borg, $33 \%$ of the fished shrimps in total. In addition, Egypt imports about 10,000 to 15,000 tons of Shrimp yearly. However, only about 3500 tons are whole shrimps while the rest are peeled before importing [27]. The report shows that about 1,600 tons are imported through Demiatta and 1100 through Alexandria [28,29]. Another 900 Tons of Shrimp shells can be derived from these imported resources. The total number is 3,400 tons, which is globally worth of 340,000 USD annually if not processed [24].

\section{Results}

The global price of plastics in general ranges between $\$ 1250$ and $\$ 1500$, differing in terms of type, and source, with a density of around $0.95 \mathrm{~g} / \mathrm{cm}$ (gram per centimeter). Comparatively, the global price of chitosan ranges between $\$ 10,000$ and $\$ 1,000,000$ differing in terms of type, sources, as well as quality and application. However, our researchers have been capable of reducing the costs to 7,000. As well, chitosan scores less in density compared to plastic, that compared to 0.95 in plastics, it is around 0.2 to 0.8 , which means that chitosan can be almost 5 times denser than polymer plastics in some cases. Economically, this means that chitosan can be 5 times more effective without reducing the cost, which would make chitosan competitive with polymer-based plastics. Furthermore, our researchers expect the cost to go as low as $\$ 2,000$ if a method was applied to be capable of reusing the acids and alkyls used in the manufacturing of chitosan.

\section{Conclusion}

Environment-friendly policies are no longer a luxury for developed economies alone, developing countries as well can improve their whole economies while also being environment friendly. The amounts of accumulated plastics wastes can at least be limited by shifting the businesses interests from synthetic to several biodegradable interests. While synthetic plastics cost around 1500 USD/Ton, chitosan, a natural polymer cost around 2000USD. Relatively, the costs are somehow equal given the fact that chitosan is almost half as dense as most plastics. In addition, there are the uncalculated costs of disposing of synthetic plastics as well as the damage that they contribute to the environment. From many perspectives, it would be more feasible to use chitosan for plastic bags than it would be to use synthetic plastics.

\section{Acknowledgment}

The authors kindly thank Newton-Mosharfa fund, Science \&Technology development Fund in Egypt (STDF), British council for funding this project.

\section{References}

1. (2016) Competitive Market Share \& Forecast. Global Market Insights, insights.

2. Le Guern Lytle C (2016) When the mermaids cry: The Great Plastic Tide.

3. Cereceda R (2016) France bans plastic bags, what about the rest of the EU. Euronews.

4. Coren MJ (2016) It won't be long before all our plastics come from plants instead of oil.

5. AbouHagra A (2017) consultant, chamber of trade, Federation of Egyptian Industries, for technical affairs, January, Open Interview.

6. (2017) Chem Orbis Connecting Markets.

7. (2017) Chitosan production line offer.

8. (2012) Demand for Biodegradable Plastics Increasing.

9. (2015) Biodegradable Plastics market.

10. European Bio-plastics. "Market drivers".

11. Kaeb H, Dammer L, Carus M, Aeschelmann F (2016) Market study on the consumption of biodegradable and compostable plastic products in Europe.

12. (2016) Plastic Bags Consumption Facts.

13. Le Guern Lytle C (2016) When the mermaids cry: The Great Plastic Tide.

14. (2015) CEBR Report. 
15. (2015) Controlled Life Plastic Technology.

16. [2016] Egyptian Plastic exporters and Manufacturers Association.

17. (2007) How is the thickness of plastic bags measured?

18. Competitive Market Share \& Forecast, 2016 - 2024. (2016). Global Market Insights.

19. Faisal M, Elhusseiny A, Chbib H, Samy I, Everitt NM, et al. Extractiion of degradable biopolymer material from shrimp shell waste by two different Methods [Scholarly project].

20. (2017) United Nations Environmental Program from unep-wcmc.org, p. 24.

21. United States Plastic Bag Market (2016) Analysis and Forecast to 2020 U.S. is the leader in global imports of plastic bags, accounting for an $18 \%$ share - Research and Markets.
22. (2015) Global Plastic Production rises, Recycling lags.

23. Gergely M (2010) Challenges and Opportunities A Summary on Industrial and Municipal Solid Waste Management in Egypt.

24. Temraz M (2017) The experimental start of the buying of trash from the citizens in Cairo. The Seventh Day.

25. Yan N, Chen X (2015) Sustainability: Don't0020 Waste Seafood Waste. Nature. Retrieved March 524(7564): 155-157.

26. Love DC, Fry JP, Milli MC, Neff RA (2015) Wasted seafood in the United States: quantifying loss from production to to consumption and moving toward solutions. Global environmental Change 35: 116-124.

27. General Authority for Fish Resources Development.

28. Federation of Egyptian Industries.

29. (2017) High Density chitosan.

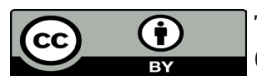

This work is licensed under Creative Commons Attribution 4.0 License

To Submit Your Article Click Here: Submit Article

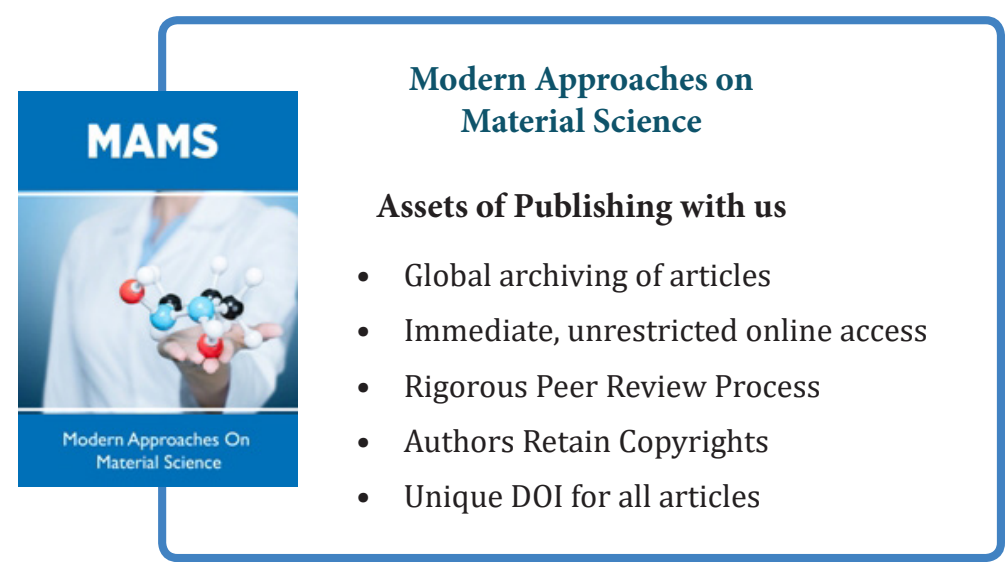

